\title{
The East Indian Water World 1709-1760: A comparison of two Dutch manuscript atlases
}

\author{
Ferjan Ormeling \\ Explokart Research Group, University of Amsterdam, F.J.Ormeling@uva.nl
}

Keywords: Manuscript atlases, Toponymy, Southeast-Asia

\begin{abstract}
:
In 1709 Isaak de Graaf, chief cartographer of the Dutch United East India Company (VOC) in Amsterdam, produced a manuscript atlas, called Atlas Isaak De Graaf (or Atlas Amsterdam), after him. This atlas portrayed the trading area of the VOC, and ranged from the Cape of Good Hope to Japan. It showed the countries around the Indian Ocean and in Southeast Asia. Two generations later (1759/60), Gerrit de Haan, chief cartographer at the VOC's other map establisment, situated in Batavia (present-day Jakarta), did likewise and produced another manuscript atlas of the VOC trading area. Both atlases have been reproduced in facsimile, the Atlas Isaak de Graaf as volume I of the Comprehensive atlas of the Dutch East India Company, while all sheets of the De Haan atlas were reproduced inserted in volumes II-VII of the same publication For both atlases place name indexes have been produced (with 16000 and 8400 names respectively) and, on the basis of the comparison of these two name sets, conclusions can be drawn regarding the changes in naming behaviour of Dutch mariners between 1700 and 1760. On the basis of the place name spellings, more use has been made of British and French maps for the later atlas, while the former contained more names derived from Portuguese maps.
\end{abstract}

The Atlas Isaak de Graaf originally contained some 187 maps $(53 \times 73 \mathrm{~cm}), 175$ of which have been preserved, amongst which there are many large-scale maps of fortifications and town plans with only a few names. The atlas by Gerrit de Haan, called Ligtende zeefakkel of de geheele Oost-Indische waterweereldt ('Shining see-torch or the complete EastIndian water world'), contained 50 maps (formaat?) (with 8 town area and 42 overview maps). Apart from one map posthumously added to the Atlas de Graaf, all the maps in the De Haan atlas were new, and - in theory - based on more recent observations.

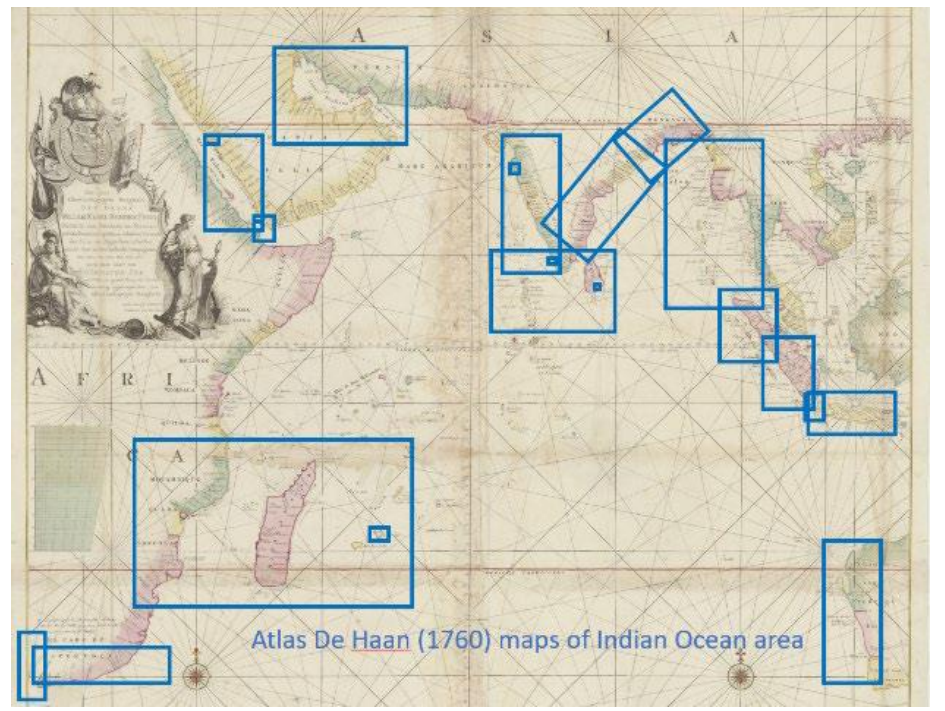

Figure 1. Index of the maps bordering the Indian Ocean in the De Haan atlas (1760).

While the De Graaf atlas presents an uninterrupted series of overview maps of the whole trading are, the later atlas is more focused on specific trading areas, omitting areas in-between, as can be seen in figure 1 for the Indian Ocean. Its coverage of present-day Indonesia is much more detailed, though, as apparently the Dutch had become more familiar with the whole eastern part of the archipelago, instead of its early focus on Ambon, Banda and Halmahera. 
The nature of the overview maps in both atlases is the same they are homogeneously executed, with red script for names that are drawn in the sea, and black names that fall on land. They serve as small-scale hydrographic charts, showing only coastal towns, bays, capes, islands and navigational; hazards. The map lettering is more modern in the De Haan atlas, and the spelling more like contemporary Dutch. In the interior of the depicted islands, side views of mountains are incorporated that also serve as navigational beacons.

Comparison of the contents of the two atlases suggests changes in the focus of mercantile operations of the VOC, as there is less interest for the African coast and for Kerala in the De Haan atlas, and more for the Philipines and Eastern Indonesia. Neither atlas shows any maps for Borneo, apparently this large island did not present any opportunity for trading. Although Australia did not present any commercial interest either, its western coasts were extensively portrayed in both atlases. Of course, comparison of the two atlases also shows the advances in geographical knowledge of Southeast-Asia. An example is shown in figures 2 and 3 for the isle of Java.

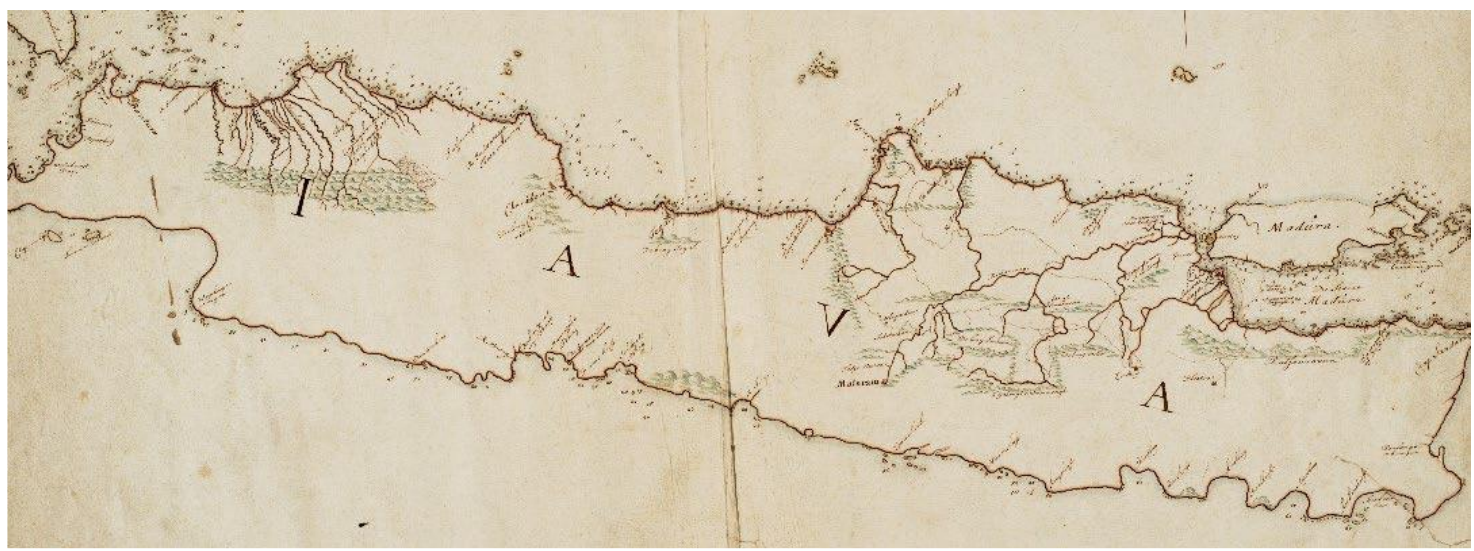

Figures 2 and 3 Java as portrayed in 1709 (above) and 1760 (below).

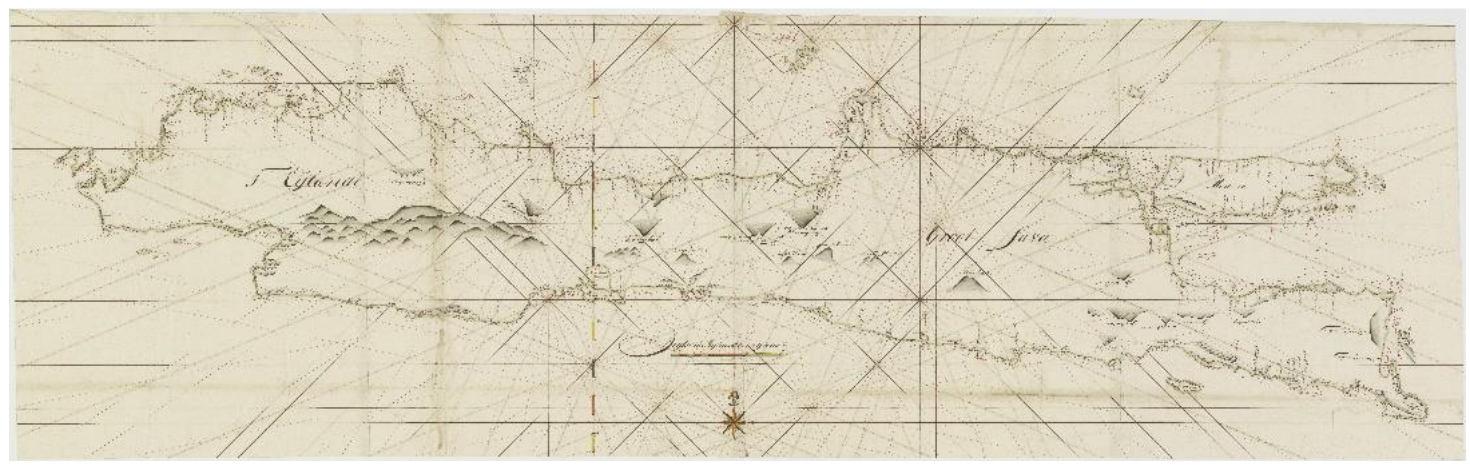

\section{References}

The Comprehensive atlas of the Dutch East India Company was published in 7 volumes by Asia Maior Publishing House, Voorburg 2006-2010. It can now also be accessed on line through the National Archive in The Hague.

Ron Guley (2015) In de kaart gekeken. Gerrit de Haan, baas-kaartenmaker van de VOC in Batavia. 